https://dx.doi.org/10.4314/jpb.v17i2.3

Vol. 17 no. 2, pp. 96-104 (September 2020)

http://ajol.info/index.php/jpb

\section{Journal of \\ PHARMACY AND BIORESOURCES}

\title{
Formulation and evaluation of detarium oil based organogel for sustained release of metronidazole via topical delivery
}

\author{
Margaret O. ILOMUANYA ${ }^{1 *}$, Uloma N. UBANI-UKOMA ${ }^{1}$, Abimbola A. SOWEMIMO ${ }^{2}$, \\ Gbemisola W. AKANDE ${ }^{1}$ and Pal KUNAL ${ }^{3}$ \\ ${ }^{I}$ Department of Pharmaceutics and Pharmaceutical Technology, Faculty of Pharmacy. University of Lagos, PMB \\ 12003, Surulere, Lagos. Nigeria. \\ ${ }^{2}$ Department of Pharmacognosy, Faculty of Pharmacy, University of Lagos, PMB 12003, Surulere, Lagos. Nigeria. \\ ${ }^{3}$ Department of Biotechnology and Medical Engineering, National Institute of Technology, Rourkela. India.
}

Received 26 ${ }^{\text {th }}$ March 2020; Accepted $3^{\text {rd }}$ August 2020

\begin{abstract}
The rationale for this study was to increase the absorption of model drug metronidazole by formulating an organogel using detarium oil in place of conventional oils used in drug formulation such as liquid paraffin. The organogels were prepared by fluid-filled mechanism using metronidazole as the model drug. The drug-surfactant mixtures were dissolved in oil followed by the addition of water which led to the formation of organogels at specific compositions. The formulations were analyzed by microscopy, rheology, in vitro drug release and X-ray diffraction (XRD). Microscopic studies revealed the gels contained clusters of water-filled spherical structures. FTIR study showed compatibility of components of the organogels. DSC result showed all the organogels released heat during formation. The viscosity of the organogels showed an elastic flow followed by a non-elastic phase. The cumulative percentage release of metronidazole was found to be between $63 \%$ and $85 \%$ at the end of $10 \mathrm{~h}$, with OGM 9 having the highest release. XRD result indicated the crystalline nature of the organogels. Metronidazole release from the organogels indicated dissolution, shape, size, and surface area dependent release. The results also showed good compatibility of all the excipients. Sustained release metronidazole organogel was successfully developed using detarium oil.
\end{abstract}

Keywords: Organogel; Detarium oil; Metronidazole; Topical delivery

\section{INTRODUCTION}

Topical delivery is an attractive route for local and systemic treatment. Topical formulations are diverse and include a wide variety of pharmaceutical dosage forms such as ointments, creams, lotions and gels [1]. Various experimental designs have been widely used to develop formulations such as organogels to act as potential active pharmaceutical ingredient vehicles for controlled release formulations of not only lipophilic drugs, but also hydrophilic drugs [2,3]. Organogels are semi-solid systems, in which an organic liquid phase is immobilized by a three-dimensional network composed of self-assembled, intertwined gelator fibres [4]. There are two main types of organogels namely fluid-filled organogels and solid-fibre based organogels. They are thermo-reversible and can accommodate both hydrophilic and hydrophobic compounds within the gel structure [5,6]. Ease of preparation,

*Correspondence. E-mail: milomuanya@unilag.edu.ng Tel: +234-8033295077.

ISSN 0189-8442

(cc) BY-NC 2020. Published by Faculty of Pharmaceutical Sciences, University of Jos, Nigeria. Under Creative Commons Attribution-Non-Commercial 4.0 International License. https://creativecommons.org/licenses/by-nc/4.0/ 
thermodynamic stability, and enhanced topical performance along with biocompatibility makes the organogel a vehicle of choice for topical drug delivery, which not only gives localized effect, but also systemic effect through percutaneous absorption [7]. Despite their liquid composition, these systems demonstrate the appearance and rheological behavior of solids [8]. The thermo-reversible property of the organogels has generated much interest for the potential use of the organogels as novel drug delivery system [7-10]. The occurrence of the gel-to-sol transition above room temperature indicates that external energy must be supplied to the organogels to disrupt the three-dimensional structure and subsequent transformation of the gelled state to the sol state. Various organogel-based formulations have been designed to administer bioactive agents by different routes of administration [11]. These systems are capable of solubilizing lipophilic, hydrophilic, and amphiphilic guest molecules, including enzymes.

Detarium senegalense JF Gmelin (Leguminosae - Caesalpinioideae) commonly known as tallow tree (local names: ofo (Igbo), aluki (Hausa) is native to Tropical Africa and is about $36 \mathrm{~m}$ high. Its leaves, bark, fruits, seeds, gum and stem have found significant use including meal, enema, wash, treatment of anemia, soup thickener, treatment of skin diseases, antibacterial activity, and reduction in blood sugar [12].

The rationale for this study is to utilize readily available oil i.e. detarium that to develop an excipient carrier system for sustained drug release. Due to its micellar structure, organogel can contain both water and oil soluble ingredients and shows excellent drug permeability by diffusion through the lipid intracellular matrix of the skin $[11,13]$. Their use in delivering sustained release products is to ensure reduced dosing intervals, that is the topical product can be applied once daily compared to conventional products, which are applied as creams two to three times daily. In this study, oil extracted from the seed of Detarium senegalense was be used as the oil base for organogel formulation with metronidazole as the model drug.

\section{EXPERIMENTAL}

Materials. Caprylic triglyceride was a gift from Gattesfosse, France, Tween 80 (BDH Chemicals, England) Metronidazole powder BP ( $\geq 98 \%$ purity) (Sigma Aldrich St. Louis, MO USA), (Batch No M3761-5G), Detarium oil, methyl paraben and propyl paraben (Sigma-Aldrich St. Louis, USA). Water used in all the tests was Milli-Q water (Millipore, USA). All other chemical reagents and solvents were of analytical grade and used for this research without further purification.

Detarium oil extraction. Detarium oil was prepared according to the method of Sowemimo et al., [12,13]. Briefly the dried seeds of $D$. senegalense were harvested from Owerri, Imo, Nigeria (Latitude and longitude coordinates being 5.476310, 7.025853). A voucher specimen (FHI 56829) was identified, prepared and deposited in the Herbarium of the Department of Pharmacognosy, Faculty of Pharmacy, University of Lagos, Nigeria. $D$. senegalense seeds were oven-dried at $50^{\circ} \mathrm{C}$ overnight and ground to powder. The ground plant material $(1 \mathrm{~kg})$ was extracted cold with 3 $\mathrm{L}$ Petroleum ether $\left(60\right.$ to $\left.80^{\circ} \mathrm{C}\right)$ for $48 \mathrm{~h}$. The extract was filtered and concentrated in vacuo at $30^{\circ} \mathrm{C}$ using the rotary evaporator (BUCHI Rotavapor $^{\mathrm{TM}} \mathrm{R}-100$ Rotary Evaporator System) and stored in amber colored bottles at $8^{\circ} \mathrm{C}[12,13]$.

Formulation development. Accurately weighed surfactant mixtures were dissolved in specified amount of oil containing metronidazole, maintained at $60^{\circ} \mathrm{C} \pm 1{ }^{\circ} \mathrm{C}$ and kept on magnetic stirrer at $500 \mathrm{rpm}$. The mixture was stirred for $20 \mathrm{~min}$, after which water was added dropwise to the surfactant-oil solution with the use of a pipette until the 
formation of organogel or until the total fraction of water reached $80 \%$ of the volume of the surfactant-oil-water mixture. Based on the composition of the surfactant-oil-water mixture, the systems either formed gelled structures or remained as a liquid mixture. Gelation was considered success if the mixture failed to flow under gravity upon inversion. The final composition of the drug in the organogel was $1 \%(\mathrm{w} / \mathrm{w})$. Surfactant mixtures of caprylic triglyceride and Tween 80 were prepared to have Labrafac: Tween 80 ratios of 1:1 (OGM1 - OGM3 organogels), 1:2 (OGM4OGM6 organogels) and 1:3 (OGM7-OGM9 organogels) as shown in Table 1. Photographs of the organogels were taken using a digital camera (Nikon P1000, 36 pixel) and all the samples were kept at $25 \pm 2{ }^{\circ} \mathrm{C}$ for further analysis.

\section{Evaluation of organogel formulations}

Physicochemical properties of the formulated metronidazole organogels. The formulated organogels were evaluated for physical appearance, color and $\mathrm{pH}$. Viscosity was measured at different shearing rates. The gel microstructures were observed under the microscope. Spreadability factor for all the gels was studied on samples at time zero and after 90 days, in triplicate. A circular mold plate of glass (diameter $=20 \mathrm{~cm}$ ) with a central orifice of $1.2 \mathrm{~cm}$ diameter, was placed on a glass support plate $(20 \mathrm{~cm} \times 20 \mathrm{~cm})$ positioned over millimetric graph paper. $0.5 \mathrm{~g}$ of organogel was introduced into the orifice of the die plate and the surface levelled with a spatula. The plaque mold was carefully removed, and a glass plate of known weight was placed over the sample. After one minute, the diameter in opposing positions (as covered by the sample) was read with the aid of the graph paper scale and the average diameter calculated [14]. This was repeated via addition of other plates in one-minute intervals. Spreadability factor $\left(\mathrm{S}_{\mathrm{f}}\right)$ was calculated as the total area $\left(\mathrm{A}, \mathrm{mm}^{2}\right)$ divided by the weight applied (W, g)

$$
\mathrm{S}_{\mathrm{f}}=\mathrm{A} / \mathrm{W} \ldots \ldots \ldots \ldots \ldots \ldots \ldots \text { Equation } 1
$$

Evaluation of thermal properties of formulated metronidazole organogels. Thermal profile of the organogels was studied using Sol-gel transition study and crystallinity of the organogels were measured using X-Ray Diffraction (XRD) (D/ MAX-2500X, Rigaku, Tokyo, Japan) (scan speed of $4^{\circ}$ per minute in the $2 \theta$ range of $5^{\circ}-60^{\circ}$ ). Sol-gel transition study was carried out to evaluate the rate of transition of the organogel from sol to gel. The organogels were heated in a temperaturecontrolled water bath. The experiment was started at $30^{\circ} \mathrm{C}$ and the temperature was increased up to $80^{\circ} \mathrm{C}$ with an increment of $5^{\circ} \mathrm{C}$ every $5 \mathrm{~min}$. The samples were incubated at the specified temperature for $5 \mathrm{~min}$ and were observed by inverted test tube method. The temperature at which the gel started to flow was regarded as gel-to-sol transition. The study was done in triplicate.

In vitro drug release. Prior to in vitro drug release determination, the drug content of all the organogels were determined. Metronidazole content in organogel was measured by dissolving $0.2 \mathrm{~g}$ of organogel formulation in $100 \mathrm{~mL} 0.1 \mathrm{~N} \mathrm{HCl}$ by sonication. Absorbance was measured after suitable dilution at $237 \mathrm{~nm}$ using UV-Visible spectrophotometer (J.P. Selecta Instruments, Spain) [15]. Accurately weighed $1 \mathrm{~g}$ of the organogel samples containing $1 \% \quad(\mathrm{w} / \mathrm{w})$ metronidazole, were put into Ciprophan synthetic membrane, and introduced into a beaker containing $50 \mathrm{~mL} 0.1 \mathrm{~N} \mathrm{HCl}$, which served as the dissolution medium. At predetermined time intervals, $2 \mathrm{~mL}$ samples were taken and replaced immediately with dissolution media. The experiment was carried out for a period of $10 \mathrm{~h}$ and the amount of metronidazole released from the organogels was measured at $\lambda_{\max }$ of $237 \mathrm{~nm}$ using UVvisible spectrophotometer (J.P. Selecta Instruments, Spain). The experiments were carried out in triplicates and the release data 
was fit into different kinetic models to determine the mechanism of drug release.

Statistical analysis. The data were expressed in mean using one-way analysis of variance (ANOVA) ( \pm SD).

\section{RESULTS}

The metronidazole organogels were white to pale yellow-colored viscous preparations with smooth homogenous appearance (Figure 1A). Viscosity profile of the organogels showed an elastic flow followed by a non-elastic phase (Figure 1B). Micrograph images of the organogel formulations OGM1 - OGM9 are shown in Figure 2. Zero-, first-, and second-order, Hixon-Crowell and Korsmeyer-Peppas kinetics were employed to describe the release of metronidazole from the organogels. The release kinetics for OGM 3, OGM 6 and OGM 9 followed a Hixon Crowell release with $\mathrm{R}^{2}$ values of $0.9946,0.9939$ and 0.9901 respectively (Table 2). Metronidazole was released on parallel planes from the organogel surface, which retards further ingress of fluid and subsequently facilitates sustained metronidazole release.

Depending on the composition of the organogels, the cumulative percentage drug release of metronidazole was found to be between $63 \%$ and $85 \%$ at the end of $10 \mathrm{~h}$.
There was a corresponding increase in drug release as the formulations proceeded from OGM 1 to OGM 9. OGM 9 showed maximum percentage of drug release at the end of $10 \mathrm{~h}$, while OGM1 showed the least percentage drug release. The $\mathrm{pH}$ of the formulations fell between 5.83 and 6.72 (Table 3) which is considered acceptable to avoid the risk of irritation upon application to the skin [13]. The XRD profile of the organogels are shown in Figure 4. The organogels showed a sharp peak at $2 \Theta$ (approx.).

\section{DISCUSSION}

Formulation of organogels is gaining importance in the pharmaceutical industries. This is attributable to the ease of formulation and thermo reversibility of the formulations, which they possess over the conventional dosage forms. This research studied the formulation, characterization and evaluation of detarium oil-based organogel for topical delivery of metronidazole.

Detarium oil extracted from the seed of D. senegalense was utilized as the oil base for the organogel formulations. Caprylic triglyceride and Tween 80 were used as surfactant blend to create an elastic phase, which facilitated solidification of the formulation at room temperature (Figure 1A) and a flow at body temperature of $37^{\circ} \mathrm{C}$.

Table 1: Composition of $20 \mathrm{~mL}$ metronidazole organogel samples

\begin{tabular}{llllll}
\hline Formulations & $\begin{array}{l}\text { Caprylic } \\
\text { triglyceride }(\mathrm{mL})\end{array}$ & $\begin{array}{l}\text { Tween } \\
80(\mathrm{~mL})\end{array}$ & $\begin{array}{l}\text { Water } \\
(\mathrm{mL})\end{array}$ & $\begin{array}{l}\text { Detarium } \\
\text { oil }(\mathrm{mL})\end{array}$ & $\begin{array}{l}\text { Metronidazole } \\
(\mathrm{g})\end{array}$ \\
\hline OGM1 & 4.60 & 4.60 & 4.80 & 6.00 & 0.2 \\
OGM2 & 6.15 & 6.15 & 3.60 & 4.10 & 0.2 \\
OGM3 & 2.00 & 2.00 & 6.00 & 10.00 & 0.2 \\
OGM4 & 3.10 & 6.10 & 4.80 & 6.00 & 0.2 \\
OGM5 & 4.10 & 8.20 & 3.60 & 4.10 & 0.2 \\
OGM6 & 1.33 & 2.67 & 6.00 & 10.00 & 0.2 \\
OGM7 & 2.30 & 6.90 & 4.8 & 6.00 & 0.2 \\
OGM8 & 3.10 & 9.20 & 3.60 & 4.10 & 0.2 \\
OGM9 & 1.00 & 3.00 & 6.00 & 10.00 & 0.2 \\
\hline
\end{tabular}



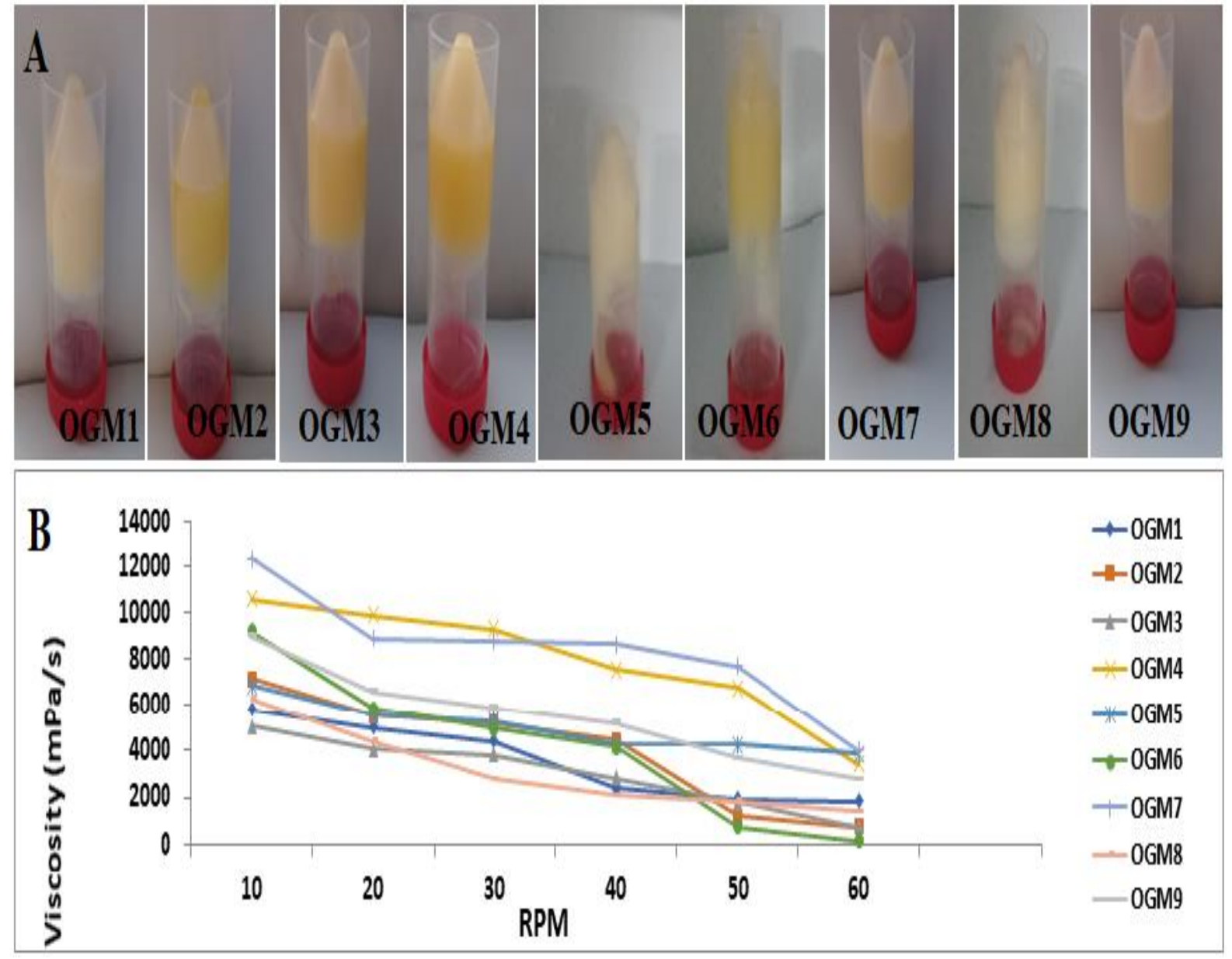

Fig. 1 (A) Photographs of the organogels (B) Effect of increased shearing on viscosity of the formulated organogels.
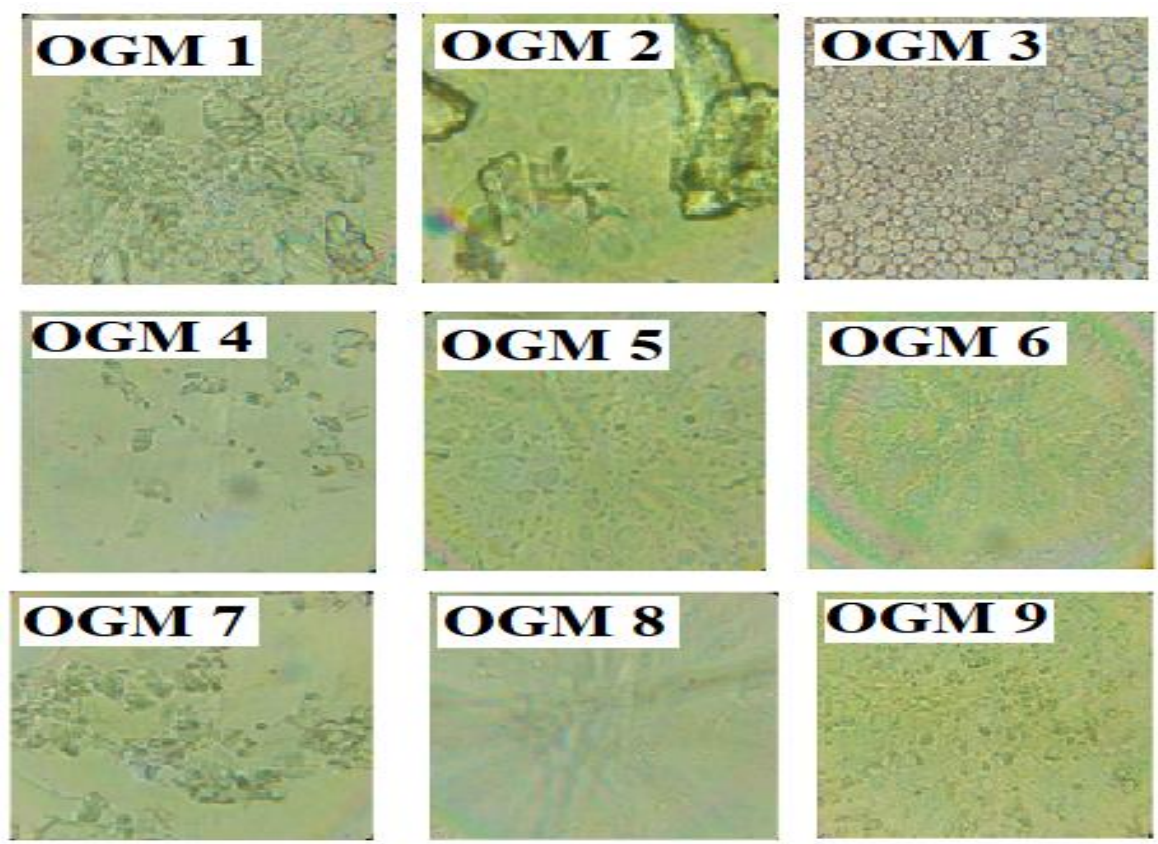

Figure 2: Micrographs of the formulated organogels

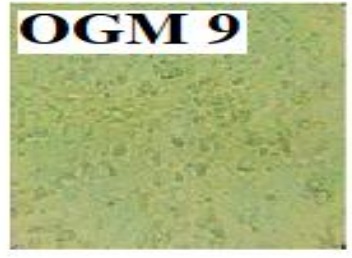




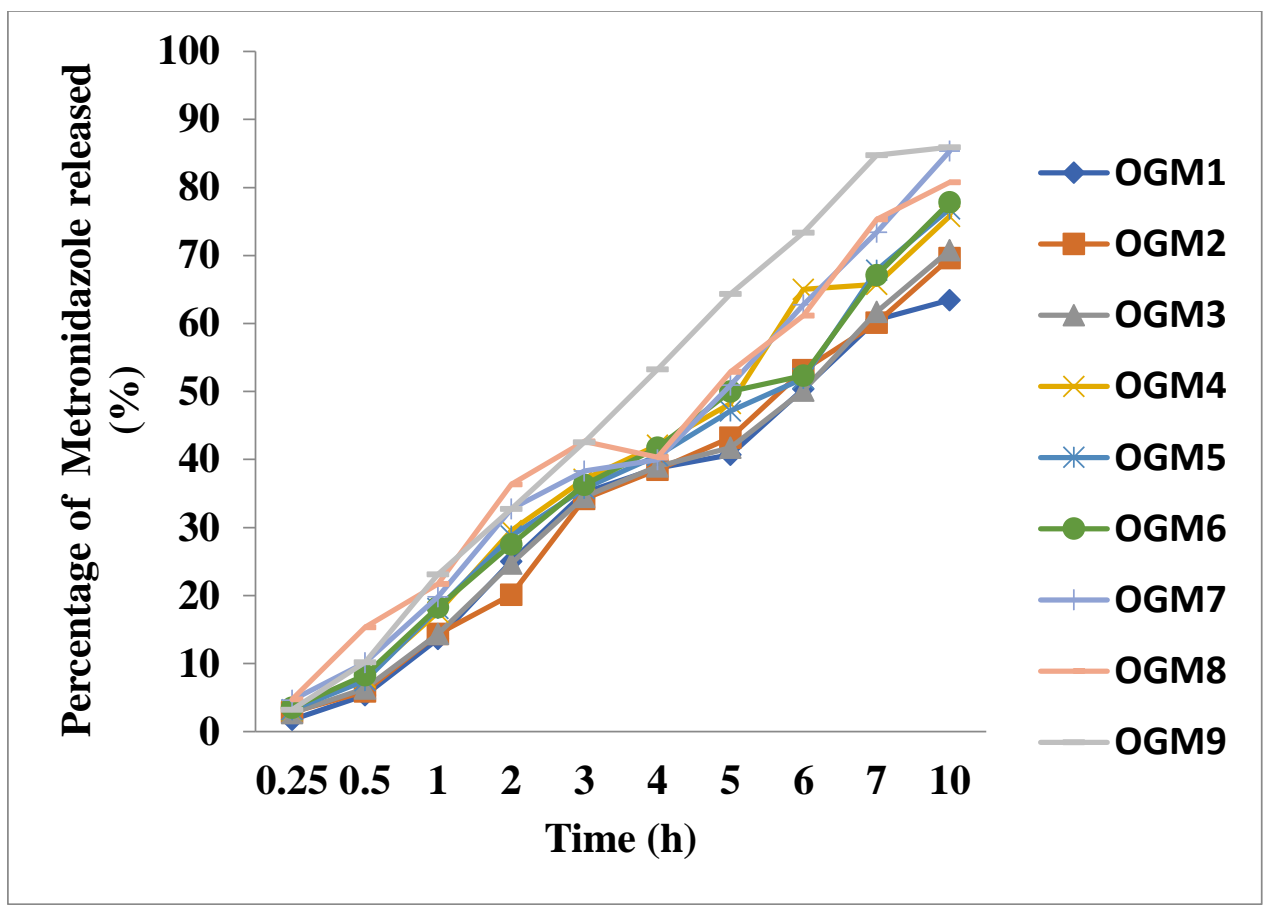

Figure 3: Percentage of metronidazole released against time in hours

Table 2: Kinetics of drug release

\begin{tabular}{cccccc}
\hline \multirow{2}{*}{ Formulations } & \multicolumn{5}{c}{ Kinetic drug release model } \\
\cline { 2 - 6 } & Zero order & First order & Higuchi & Korsmeyer Peppas & Hixson Crowell \\
\hline OGM1 & 0.9192 & 0.9587 & 0.9820 & 0.9567 & 0.9921 \\
OGM2 & 0.9586 & 0.9860 & 0.9894 & 0.9850 & 0.9920 \\
OGM3 & 0.9580 & 0.9842 & 0.9888 & 0.9801 & 0.9946 \\
OGM4 & 0.9379 & 0.9778 & 0.9848 & 0.9718 & 0.9934 \\
OGM5 & 0.9577 & 0.9734 & 0.9833 & 0.9717 & 0.9907 \\
OGM6 & 0.9619 & 0.9815 & 0.9894 & 0.9772 & 0.9939 \\
OGM7 & 0.9642 & 0.9668 & 0.9781 & 0.9815 & 0.9861 \\
OGM8 & 0.9314 & 0.9566 & 0.9682 & 0.9438 & 0.9722 \\
OGM9 & 0.9164 & 0.9543 & 0.9789 & 0.9573 & 0.9901 \\
\hline
\end{tabular}

Table $3 \mathrm{pH}$ values, Spreading coefficient, Sol-gel transition temperature and drug content of the metronidazole organogel formulations.

\begin{tabular}{lllll}
\hline $\begin{array}{l}\text { Organogel } \\
\text { formulations }\end{array}$ & $\mathrm{pH}$ & $\begin{array}{l}\text { Spreadability factor } \\
\left(\mathrm{S}_{\mathrm{f}}\right)\left(\mathrm{mm}^{2} \mathrm{~g}^{-1}\right)\end{array}$ & $\begin{array}{l}\text { Sol gel } \\
\text { temperature }\left({ }^{\circ} \mathrm{C}\right)\end{array}$ & $\begin{array}{l}\text { Drug } \\
\text { content }(\%)\end{array}$ \\
\hline OGM1 & $6.15 \pm 0.01$ & $19.99 \pm 2.82$ & $37 \pm 0.3$ & $99.7 \pm 0.33$ \\
OGM2 & $6.56 \pm 0.06$ & $21.13 \pm 1.70$ & $37.2 \pm 0.3$ & $98.6 \pm 0.53$ \\
OGM3 & $5.88 \pm 0.06$ & $23.09 \pm 2.10$ & $37.2 \pm 0.8$ & $99.0 \pm 1.07$ \\
OGM4 & $6.16 \pm 0.10$ & $26.01 \pm 1.55$ & $37.5 \pm 0.2$ & $101.1 \pm 0.05$ \\
OGM5 & $6.60 \pm 0.11$ & $10.01 \pm 1.01$ & & $103.3 \pm 0.72$ \\
OGM6 & $5.60 \pm 0.05$ & $20.09 \pm 2.07$ & $\overline{36.8 \pm 0.2}$ & $98.1 \pm 0.66$ \\
OGM7 & $6.19 \pm 0.08$ & $10.01 \pm 2.45$ & $37.9 \pm 0.5$ & $97.2 \pm 1.06$ \\
OGM8 & $6.72 \pm 0.92$ & $21.99 \pm 1.33$ & & $103.2 \pm 0.98$ \\
OGM9 & $5.83 \pm 0.83$ & $20.01 \pm 2.54$ & $\overline{38.2 \pm 1.2}$ & $98.8 \pm 0.65$ \\
\hline
\end{tabular}




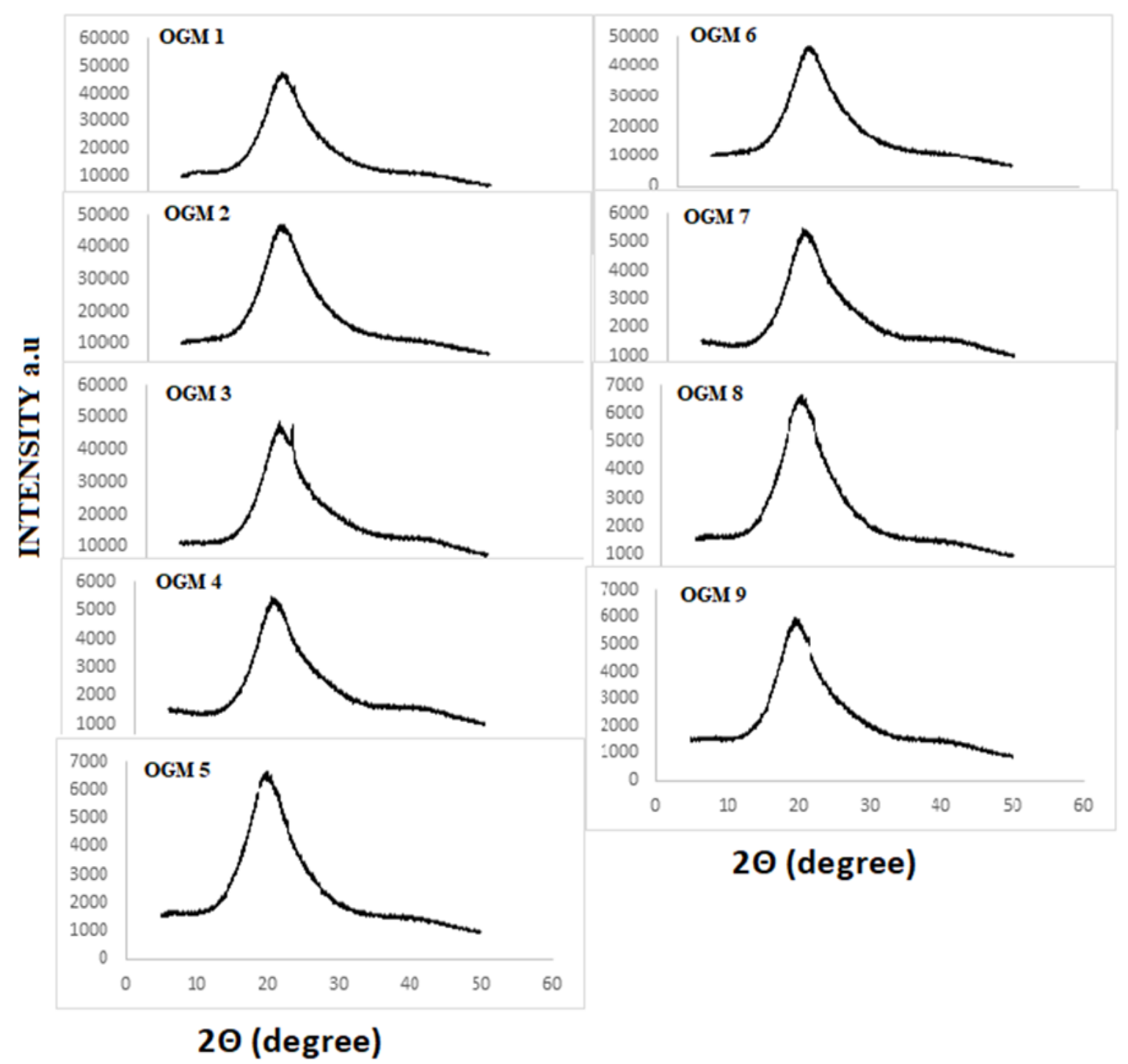

Figure 4: X-ray diffraction profiles of formulated organogels

The presence of the elastic phase may be attributed to the elastic nature of sorbitan ester organogels i.e. tween 80 present in the formulation (Table 1) as the organogelator molecule [15-17]. In this phase, the physical interactions among the gelator molecules were stronger and the applied shear was not able to dislodge the gelator molecules involved in the formation of the gelled structures via fluidfilled microstructures. As the applied shear is increased during viscosity evaluation, the hydrophobic interactions are not able to keep the fluid-filled microstructures together. This results the disruption of the 3-dimensional networked structures [17].

The $\mathrm{pH}$ of the formulations fell between 5.83 and $6.72(\mathrm{pH}$ of the human skin $\sim 5.5$ ) which is considered acceptable to avoid the risk of irritation upon application to the skin. Spreadability denotes the extent of area to which a gel readily spreads on application to the skin and it depends on the viscosity of the 
formulations and physical characteristics of the excipients used in the formulation. The therapeutic efficacy of a formulation also depends upon its spreading value [18, 19] A more viscous formulation would have lower spreadability factor. OGM 5 and OGM 8 had the highest spreadability factor of $10.01 \pm 1.01$ $\mathrm{mm}^{2} / \mathrm{g}$ and $10.01 \pm 2.45 \mathrm{~mm}^{2} / \mathrm{g}$ respectively (Table 3), these formulations did not form organogels and hence had higher flow characteristics when compared to the other formulations hence would be unsuitable for sustained drug release.

The microstructures of the organogels were studied under the light microscope and the micrographs revealed that the organogels contained clusters of water-filled spherical, granular and tubular structures which led to the formation of a 3-dimensional network structure (Figure 2). The gel-sol transition temperatures were found to be between $36.7^{\circ} \mathrm{C}$ and $38.2^{\circ} \mathrm{C}$ (Table 3 ). As the temperature is increased, there is a corresponding increase in the surface free energy with a subsequent increase in the mobility of the self-assembled structures formed by the gelator. With further increase in the temperature, the interaction among the self-assembled structures is abolished, and hence results in the disruption of the network structure, which causes the system to flow freely. Hence at body temperature there will be seen an increase in the flow of the formulation which will in turn facilitate drug release.

Release of drug molecules from formulations depend on the interactions between drug and surfactant and/or drug partition coefficient and drug solubility in the oil and aqueous phase [16]. The in vitro drug delivery studies were carried out using $1 \%$ (w/w) metronidazole loaded organogels. The organogel formulation was able to trap the model drug metronidazole and prolong its release over 10 hours. Different equations were used to fit the experimental data to the theoretical curve. The release kinetics for
OGM 3, OGM 6 and OGM 9 followed a zeroorder release. A regression coefficient value $\mathrm{R}^{2}$, close to 1 indicates zero-order release which implies that constant amount of the metronidazole will be released per unit time irrespective of its concentration in the gel. This release mechanism ensured a controlled and prolonged release of metronidazole hence reducing dosing frequency on application. OGM 1, 2, 4, 5, 7 and 8 followed HixonCrowell with $\mathrm{R}^{2}$ values of $0.996,0.998,0.999$, 0.996, 0.997 and 0.997 respectively. This suggested that the rate of metronidazole release from the organogel was dependent on the characteristic change in surface area and diameter of the globules as they erode over time.

The presence of sharp peaks X-ray diffraction profiles of formulated organogels indicated the crystalline nature of metronidazole, which may be attributed to the highly ordered molecular structure. The presence of the peaks at the same position indicated that the composition of the organogels is similar.

In conclusion, this study reported the successful development of sustained release metronidazole organogel by fluid-filled mechanism using detarium oil as a base, with the most critical factors in organogel formulation being the ratio of water to the gelator molecule, that is, tween 80 contained in the formulation. The results also showed good compatibility of all the excipients with the active ingredient in the formulation of the organogels. Based on preliminary studies, detarium oil can be used as a base for sustained drug release via topical application as a novel excipient. This can also serve as a source of revenue for the agricultural industry whilst boosting local manufacture of pharmaceutically relevant raw materials. 


\section{REFERENCES}

1. Suzuki, M. (2007) Organogelation by Polymer Organogelators with a L-Lysine Derivative: Formation of a Three-Dimensional Network Consisting of Supramolecular and Conventional Polymers. Chemistry - A European Journal, 13, 81938200 .

2. Suzuki, M., and Hanabusa, K. (2010) Polymer organogelators that make supramolecular organo-gels through physical cross-linking and self-assembly. Chem. Soc. Rev., 39, 455 - 463.

3. Karande, P., Mitragotri, S. (2009) Enhancement of transdermal drug delivery via synergistic action of chemicals. Biochim Biophys Acta, 1788, 2362-2373.

4. Ashara, K.C., Paun J.S., Soniwala, M.M., Chavada, J.R., and Mori, M. (2014) Micro-emulsion based emulgel: a novel topical drug delivery system. Asian Pac J Trop Dis 4: S27-S32.

5. Bhattacharya, C., Kumar N., Sagiri, S.S., Pal, K., and Ray, S.S. (2012) Development of span 80tween 80 based fluid-filled organogels as a matrix for drug delivery. J Pharm Bioall Sci; 4:155-63.

6. Avramiotis, S., Papadimitriou, V., Hatzara, E., Bekiari, V., Lianos, P., and Xenakis, A. (2007) Lecithin organogels used as bioactive compounds carriers. A micro domain properties investigation. Langmuir; 23:4438-47.

7. Chen, Z., Li, F., Yang, H., Yi, T., and Huang, C.A. (2007) Thermostable and long-term-stable ionicliquid-based gel electrolyte for efficient dye-sensitized solar cells. Chem Phys Chem 8:1293.

8. Hadidi, N., and Nazari, R.A. (2009) Formulation and Optimization of Micro emulsionBased Organogels Containing Propranolol Hydrochloride Using Experimental Design Methods. Daru;17(3):217-224.

9. Raza, K., Kumar, M., Kumar, P., Malik, R., and Sharma, G. (2014) Topical Delivery of Aceclofenac: Challenges and Promises of Novel Drug Delivery Systems. Biomed Res Int 2014:406731.

10. Pathan, I.B., and Setty, C.M. (2009) Chemical penetration enhancers for transdermal drug delivery systems. Trop J Pharm Res, 8, 173-179.

11. Sahoo, S., and Kumar, N. (2011) Organogels: Properties and applications in drug delivery. Designed Monomers and Polymers, 14, 95-108.
12. Ilomuanya, M.O., Ekerebe, Z., Cardoso-

Daodu, I., Sowemimo A.A. (2020) Formulation and Evaluation of sunscreen cream using Detarium senegalense oil as base. Tropical Journal of natural products research 4(4):141-145. https://doi.org/10.26538/tinpr/v4i4.5

13. Pandey, M.S., Belgamwar, V.S., and Surana, S.J. (2009) Topical delivery offlurbiprofen from pluronic lecithin organogel. Ind J Pharm Sci 71:8790.

14. Kale, S., Sonawane, A., Ansari, A., Ghoge, P., Waje, A. (2010) Formulation and in-vitro determination of sun protection factor of Ocimum basilicum, Linn. leaf oils sunscreen cream. International Journal of Pharmacy and Pharmaceutical Sciences.2(4):147-149.

15. Rao, M., Sukre, G., Aghav, S., \& Kumar, M. (2013). Optimization of Metronidazole Emulgel. Journal of pharmaceutics, 2013, 501082. https://doi.org/10.1155/2013/501082

16. Upadhyay KK, Tiwari C., Khopade AJ, Bohidar HB and Jain SK (2007) Sorbitan Ester Organogels for Transdermal Delivery of Sumatriptan, Drug Development and Industrial Pharmacy, 33:6, 617-625, DOI: 10.1080/03639040701199266

17. Satapathy, S., Singh, VK., Sagiri, S., Agarwal, T., Banerjee, I., Bhattacharya, MK., Kumar, N., Pal, K. (2015). Development and Characterization of Gelatin-Based Hydrogels, Emulsion Hydrogels, and Bigels: A Comparative Study. Journal of Applied Polymer Science. 132. https://doi.org/10.1002/app.41502

18. Ilomuanya, M.O., Elesho, R.F., Amenaghawon, A.N. et al. Development of trigger sensitive hyaluronic acid/palm oil-based organogel for in vitro release of HIV/AIDS microbicides using artificial neural networks. Future Journal of $\begin{array}{llll}\text { Pharmaceutical Sciences } & 6, & 1 & \text { (2020). }\end{array}$ https://doi.org/10.1186/s43094-019-0015-8

19. Ilomuanya M.O.: Hydrogels as biodegradable biopolymer formulations. In: Biopolymer-Based Formulations. Eds.: Pal K., Banerjee I., Sarkar P., Kim D., Deng W-P., Dubey N.K., Majumder K., Elsevier, Cambridge 2020, 561-585. https://doi.org/10.1016/B978-0-12-816897-4.00023-0 